\title{
El argumento de la falta de consenso regional en derechos humanos. Divergencia entre el TEDH y la Corte IDH $^{* * * * * * *}$
}

\section{The argument of the lack of regional consensus on human rights. Divergence between the EctHr and the IACtHR}

RESUMEN

Este trabajo analiza críticamente una constelación argumentativa central en el TEDH que combina inexistencia de consenso europeo con amplio margen de apreciación al Estado. Las complejidades de esta constelación suelen ser opacadas cuando algunos Estados de la región interamericana abogan por su importación. Para ello se propone distinguir diferentes usos del consenso, asî́ como también la función descriptiva y normativa del argumento, y la relación entre la existencia o ausencia del consenso europeo y la determinación del margen de apreciación del Estado. Estas complejidades permiten determinar con precisión la divergencia entre el TEDH y la Corte IDH en el uso de la falta de consenso regional en la constelación de casos referidos a la discriminación por orientación sexual, como así también proponer diversas hipótesis que traten de explorar la divergencia. Todo este camino argumentativo permite

Abogada, Universidad de Buenos Aires (UBA), LLM y Doctora en Derecho (Universität Kiel). Profesora de Derecho Constitucional (UBA) y Profesora Honoraria de Derecho Constitucional Comparado y Protección de Derecho Humanos (FAU, Univ. Erlangen/Nürnberg). Investigadora del Consejo Nacional de Investigaciones Científicas y Técnicas (CONICET). Contacto: lauraclerico@ yahoo.com

** Recibido el 26 de noviembre del 2018, aprobado el 28 de enero del 2020.

Para citar el artículo: CLÉRICO L. El argumento de la falta de consenso regional en derechos humanos. Divergencia entre el TEDH y la Corte IDH. Revista Derecho del Estado, Universidad Externado de Colombia. N. ${ }^{\circ} 46$, mayo-agosto de 2020, pp. 57-83.

DOI: https://doi.org/10.18601/01229893.n46.03

**** Agradezco a Martín Aldao por la discusión y lectura crítica de este trabajo. Versiones preliminares de este texto fueron presentadas en el SELA durante el encuentro en Puerto Rico, en la Facultad de Derecho, de la Universidad de Erlangen/Nürnberg (FAU), de la Universidad de Buenos Aires (UBA), de la PUCA de Lima; y en el Max Planck Institut de Heidelberg, agradezco a todas las personas que durante esos encuentros formularon preguntas, críticas y comentarios a este trabajo. Por último, agradezco la lectura, críticas y sugerencias de las personas evaluadoras anónimas de este texto. Los errores me pertenecen. 
seguir sosteniendo la tesis acerca de los perfiles argumentativos divergentes de las cortes regionales que está determinado por sus audiencias: por un lado, el TEDH, como una corte preocupada por los interlocutores, los Estados de la región, frente a, por el otro, la Corte IDH, preocupada por evaluar las razones o sinrazones de las restricciones a los derechos, más allá del (des)agrado de los Estados de la región.

\section{PALABRAS CLAVE}

Falta de consenso europeo, falta de consenso interamericano, enfoque argumentativo del TEDH y de la Corte IDH, divergencias, discriminación basada en la orientación sexual.

\section{ABSTRACT}

This work analyzes a central argument in the ECtHR that combines the absence of a European consensus with a wide margin of appreciation for the State. The complexities of this constellation are usually obscured when some States of the Inter-American region advocate its importation. To this end, it is proposed to distinguish different uses of consensus, as well as the descriptive and normative function of the argument, and the relationship between the existence or absence of the European consensus and the determination of the margin of appreciation of the State. These complexities allow to accurately determine the divergence between the ECtHR and the IACtHR in the use of the lack of regional consensus in the constellation of cases related to discrimination based on sexual orientation, as well as to propose various hypotheses that explore the divergence. All this argumentative path allows to continue supporting the thesis about the divergent argumentative profiles of the regional courts that is determined by their audiences: the ECtHR, as a court concerned by the interlocutors, the States of the region, in front of the IACtHR as a court concerned with evaluating the (un)reasons for the restrictions on rights, beyond the (un) pleasure of the States of the region.

\section{KEYWORDS}

Lack of European consensus - Lack of Inter-American consensus - Argumentative approach of the ECHtR and the IACtHR - Divergences - Discrimination based on sexual orientation.

SUMARIO

I. Planteamiento del problema. II) "No consensus on consensus". Ambigüedades: significados y funciones; a) Dos funciones: una descriptiva y 
otra normativa. Tres problemas; b) Consenso regional como criterio para la determinación del margen de apreciación estatal (MoA); c) Escenarios y complejidades del uso del consenso europeo; d) Argumentatio interrupta; e) La Corte IDH niega tres veces el uso del argumento de la falta de consenso regional. Divergencia con el TEDH; III) La comunidad de habla del TEDH y la de la Corte IDH. Divergencias; a) La divergencia en el uso del MoA; b) La divergencia en relación con la preocupación del TEDH por la búsqueda del consenso estatal; c) Audiencias divergentes; Conclusiones.

\section{PLANTEAMIENTO DEL PROBLEMA}

Las Cortes regionales de derechos humanos parecen tener dos misiones. Por un lado, producen estándares generales de derechos humanos a través de su jurisprudencia para que los Estados lo utilicen en el orden interno y así cumplan con sus obligaciones de acuerdo con la Convención. Por el otro lado, hacen justicia en los casos concretos. Si los Estados desconocen los estándares, resuelven los casos identificando la violación al derecho y condenado al Estado". Ahora bien, en la medida en que los Estados "consideran" que están cumpliendo en general con esos estándares en el orden interno, empiezan con diversas estrategias a cuestionar - más o menos solapadamente, según el Estado - la función de las Cortes regionales de hacer justicia en los casos concretos y, a su vez, de seguir desarrollando estándares de derechos humanos a la luz de la mejor interpretación de la convención ${ }^{2}$.

Las respuestas de las Cortes a estas tensiones no parecen ser drásticas en favor o en contra de cada uno de los extremos. Tampoco las respuestas son estrictamente similares si se comparan los sistemas de protección internacional. Esto se debe, por cierto, a las diferentes historias y razones por las que nacieron y se desarrollaron los respectivos sistemas regionales de

1 ARnARDótTIR $(2017,819-843)$. Sobre la doble misión en el SIDH, v. Corte IDH en la supervisión de sentencia en el caso Gelman c. Uruguay, entre otros.

2 En 2019 los gobiernos de Argentina, Brasil, Colombia y Paraguay, firmaron en conjunto una declaración cuestionando la actuación de los órganos principales del Sistema Interamericano de Derechos Humanos. Este pronunciamiento generó, por ejemplo, la crítica justificada de organizaciones de derechos humanos y de algunos profesores de derechos humanos, teoría del derecho y derecho constitucional de la Universidad de Buenos Aires. Estos últimos en una carta de mayo de 2019 dirigida al entonces titular del Poder Ejecutivo de la Nación, sostuvieron “[...] que la actitud de los gobiernos es verdaderamente preocupante pues, a partir de estrategias de presión, pretenden limitar la labor de la Comisión y la Corte Interamericanas, impulsándolas a escenarios regresivos y restringir el efectivo goce de los derechos humanos de las personas que se encuentran en la jurisdicción de estos países." Este tipo de debates e intercambios justifica la pertinencia y actualidad de este artículo, tal como lo apunta una de las personas que ha evaluado este trabajo en forma anónima. En general, sobre los debates acerca del papel de la Comisión y de la Corte IDH en diversos contextos, v., entre muchos otros, Abramovich (2011); TAIANa (2013, 44); Soley; Steininger (2018), Contesse (2019), Engstrom (2019). 
protección de los derechos humanos ${ }^{3}$. Por caso, una de las respuestas a esta tensión fue canalizada por el Tribunal Europeo de Derechos Humanos (TEDH) a través del énfasis puesto en el "consenso europeo". De ahí que se hable de un giro consensualista en la jurisprudencia del tribunal. Si el TEDH detecta que la mayor parte de los Estados del Consejo de Europa tienen normas que convergen en un mayor alcance del derecho en cuestión, entonces se siente mejor legitimado 4 para restringir el margen de apreciación del Estado. Así, controla la violación alegada a través de un examen de las razones estatales bien intensivo. Por el contrario, si identifica una ausencia de consenso regional, opta por el estancamiento hasta que "soplen nuevos vientos". Reconoce al Estado un amplio margen de apreciación y controla en forma leve las razones estatales dadas para la restricción de los derechos.

Quienes abrazan el uso del consenso europeo sostienen que genera previsibilidad. Los Estados pueden observar la tendencia en la región y preparar las agendas de derechos humanos, sabiendo de antemano que si la tendencia está en crecimiento ${ }^{5}$, los Estados rezagados serán sometidos a un escrutinio estricto cuando la tendencia se convierta en contundente. Acelerador, si hay consenso regional; freno, si hay ausencia de consenso.

De cara a los procesos (en diferentes grados) de consolidación de la democracia en la región interamericana ${ }^{6}$, algunos Estados alegan que se les reconozca un amplio margen de apreciación para el desarrollo interpretativo de los derechos limitables. De ahí que propongan (con voz, más o menos alta, según el caso), el uso del argumento de la falta de consenso regional a la usanza europea en el contexto interamericano ${ }^{7}$.

3 Piovesan (2011), Parra (2016); Neumann (2008, 107); Dondoli $(2018,14)$.

4 Sobre el argumento de la existencia de consenso europeo a favor una interpretación progresiva de la Convención por el TEDH y, a su vez, una reducción en el caso del margen de apreciación del Estado demandado, cfr. Kleinlein (2017, 874, 886/7); DzeHTSIARou (2015, 159); Petkova $(2013,663)$.

5 Dothan $(2018,393)$ entiende que una aplicación correcta de la doctrina del margen de apreciación ayuda al consenso emergente a lograr "resultados óptimos", en tanto implicaría para los estados un incentivo para desarrollar sus políticas de manera independiente.

6 Gargarella (2013); Spano (2014); cfr. Contesse (2016, 123); Tsereteli (2016).

7 Por ejemplo, Chile en el caso Atala (2012); Costa Rica en el caso Artavia Murillo (2012). En 2008, Neumann sostuvo que la interpretación evolutiva de la Convención requería que la Corte tuviera en cuenta el consenso regional. Esto contribuiría en favor de la aceptabilidad y efectividad del sistema interamericano [explora la relación entre consenso regional e implementación de las sentencias de la Corte IDH, BERTONI, E. (2017)]. Neuman advierte que "letting each state be the judge of its own human rights obligations, free to redefine or retract prior commitments, would negate the effect of the American Convention. But that observation does not entail that the substantive evolution of the regional human rights regime must be independent of the regional community of states" $(2008,115)$. Sin embargo, no queda en claro si implicaría un argumento para transferir la doctrina de la falta consenso en la versión europea al interamericano con todas sus complejidades o si bien es una observación que debe ser tenida en cuenta. 
Sin embargo, se opacan las complejidades que presenta la doctrina de la ausencia de consenso europeo en el contexto que la vio nacer ${ }^{8}$. Por caso, alcanza con mapear las críticas que pueden ser clasificadas en, por lo menos, dos grupos. Por un lado, están las funcionales. No atacan los presupuestos de la doctrina ni tampoco su uso por el TEDH, sino sus déficits de racionalidad. Advierten que no es claro cómo se determina el consenso ("no consensus on consensus") ${ }^{9}$, si se requiere unanimidad, mayoría (pero cuál), o cómo el TEDH selecciona la "muestra" 10 para determinar si hay convergencia o disparidad. Por el otro lado, están las críticas ${ }^{11}$ que advierten sobre sus presupuestos teóricos: la deferencia hacia los Estados, basada en la falta de consenso europeo en los Estados de la región, puede implicar la indiferencia del TEDH respeto de la posición de las poblaciones en situación de desventaja estructural ${ }^{12}$.

Asimismo, los proponentes de la transferencia al sistema interamericano no delimitan las complejidades que presenta el tipo de consenso que está en la trastienda del europeo ${ }^{13}$. Por ello, primero distinguiremos diferentes usos del consenso para detenernos en el uso del consenso europeo que supone un ejercicio de derecho comparado en el marco de la adjudicación en derechos humanos. A su vez, la insistencia en la migración del argumento europeo parece opacar su contracara, el argumento de la ausencia de consenso europeo en la adjudicación en derechos humanos que, sustentamos, desafía la suficiencia del argumento del consenso europeo como argumento autónomo. En suma, el objetivo general ${ }^{14}$ de este trabajo es analizar críticamente las complejidades del uso del criterio de la inexistencia de consenso europeo para determinar un amplio margen de apreciación al Estado ${ }^{15}$. Para ello,

8 Føllesdal, $(2017,368)$ sostiene la "exportación" al contexto interamericano del margen de apreciación en combo con la doctrina del consenso europeo. Advierte que la exportación requiere retoques ("una doctrina más precisa y consistente"). Sin embargo, deja abierto el tratamiento de las complejidades específicas de la doctrina de la falta de consenso europeo.

9 Wildhaber $(2013,260)$ : sosteniendo que varía de acuerdo con el contexto.

10 SMEt (2013) en relación con el caso tedH, X. and Others v. Austria (Part II).

11 V. otras críticas en: Dzehtsiarou (2015, 115-142).

12 LandFried (2017); Shahid (2017, 193); SJöholm (2018, 154); FARAhat (2015); AldaO (2019)

13 En este trabajo el foco está en la relación argumentativa entre consenso regional, margen de apreciación y examen de proporcionalidad. Sin embargo el argumento del consenso europeo es utilizado en otras relaciones argumentativas, por ejemplo, para interpretar términos vagos, DzEHTSIAROU, Kanstantsin (2009). Estas últimas relaciones argumentativas exceden el objeto de este trabajo.

14 Agradezco a una de las personas evaluadoras anónimas de este texto que me sugirió enunciar los objetivos en forma expresa aunque en la versión anterior eran "fácilmente identificables en el cuerpo del texto del artículo".

15 Por lo demás, nuestra crítica no alcanza al uso del argumento de derecho comparado en general y como judicial engagement. Este uso no es problemático. No significa acordar con la decisión o el razonamiento, sino utilizar la comparación para refinar y delimitar las cuestiones que se debaten en el caso; para incluir esos argumentos en el proceso deliberativo (no para seguirlos ciegamente) que debería implicar la justificación de la solución a cualquier caso. En otro lugar 
los objetivos específicos son: distinguir diferentes usos argumentativos del consenso, la función descriptiva y normativa del consenso, y la relación entre la existencia o ausencia del consenso europeo y la determinación del margen de apreciación del Estado; reconstruir los escenarios argumentativos diversos en que se usa el consenso europeo; analizar críticamente la ausencia de consenso europeo en la adjudicación en derechos humanos (argumentatio interrupta); y, por último, reconstruir la divergencia entre el TEDH y la Corte $\mathrm{IDH}^{16}$ en el uso de la falta de consenso regional, así como también proponer diversas hipótesis que traten de explicar la divergencia. Todo este camino argumentativo nos permite seguir delineando (y sosteniendo la tesis acerca de) los perfiles argumentativos divergentes de las cortes regionales determinados por sus audiencias: por un lado, el TEDH, como una corte regional preocupada por sus interlocutores los Estados de la región, frente a, por el otro, la Corte IDH preocupada por evaluar las razones o sinrazones de las restricciones a los derechos, más allá del (des)agrado de los Estados de la región ${ }^{17}$.

II. "NO CONSENSUS ON CONSENSUS". AMBIGÜEDADES:

SIGNIFICADOS Y FUNCIONES

El consenso puede ser entendido en diversos sentidos. Una revisión de la jurisprudencia del TEDH arroja como resultado al menos cuatro apreciaciones diferentes: a) consenso basado en reglas que surgen de la comparación de las normas y prácticas de los Estados de la región; b) consenso basado en tratados internacionales y otras producciones de organismos internacionales; c) consenso interno en el Estado demandado ${ }^{18}$; d) consenso de especialis-

se sostuvo que la Corte IDH debía tener en cuenta las normas, prácticas y jurisprudencia relevante de los tribunales internos para incluirlas en el debate de la cuestión en estudio. Sin embargo de esto no se sigue que deba reconocer a los Estados un amplio margen de apreciación si no hay consenso regional; cfr. CLÉRICO (2011); CONTESSE (2017): CODDOU (2017; 2018), sobre enfoque bottom-up que lleve a la Corte IDH a considerar la jurisprudencias de los tribunales domésticos sobre la cuestión debatida. JACKSON $(2005,109)$; (2010, caps. 2 y 3$).$

16 En forma reciente, Burgorgue-Larsen (2018: 187), sosteniendo que el consenso europeo es fundamental en el sistema europeo pero no tanto en el interamericano y es casi inexistente en el africano. Cfr. LiXINSKY (2017).

17 Clérico (2017); ClérICO (2019).

18 El consenso interno en el Estado demandado se refiere a las opiniones de las personas, de los órganos estatales y agencias que conforma ese estado, entre otras. El análisis empírico de la jurisprudencia del TEDH demuestra que no es el más utilizado. Este consenso se puede referir a: a) declaraciones del parlamento o de los tribunales o de otras agencias en el orden interno; b) basado en una práctica que se ataca como violatoria de un derecho; c) basado en el resultado de un referéndum o similar. Cada una de estas fuentes puede ser problemática a la luz de la función de un tribunal de derechos humanos como foros de reconocimiento y discusión de las voces que son estigmatizadas e invisibilizadas en los órdenes internos ya que las mismas no se encuentran en igualdad de armas en el debate y definición de las acciones y políticas estatales que las afectan. Sobre el uso de este tipo de consenso en TEDH, “A. B C. vs. Irlanda” (2010), 
tas ${ }^{19}$. Los dos primeros son los más utilizados en la jurisprudencia del TEDH y los que interesan a los efectos de este trabajo.

Por un lado, se lo utiliza como a) consenso europeo, se observan las normas y las prácticas de los Estados del Consejo de Europa para determinar si hay convergencia en la interpretación de una cuestión controvertida. Si se identifica una convergencia, el TEDH habla de "consenso europeo" ${ }^{20} \mathrm{o}$ "comon european approach". El tribunal suele presentar el resultado de la comparación. El proceso de comparación ${ }^{21}$ está institucionalizado ${ }^{22}$. Sin embargo, no aparece como tal en la justificación de la sentencia. En la sentencia sí aparece el resultado de la comparación, bajo el formato de una enumeración no exhaustiva del estado de la cuestión jurídica en los Estados que fueron tomados para la comparación.

Por el otro lado, está el b) consenso o tendencia internacional. En la argumentación sobre derechos humanos es frecuente recurrir a las producciones de otros sistemas regionales o internacionales para determinar cómo fue tratada la cuestión en disputa y qué soluciones se propusieron, por ejemplo, en resoluciones, informes, comentarios generales, consideraciones finales, de diferentes órganos de protección de derechos humanos de Naciones Unidas

como asimismo acerca del problema de la determinación del consenso interno, v. De Londras; Dzehtsiarou (2013, 250); Álvarez (2017), SJöHolm, (2018, 146).

19 El consenso de especialista se refiere al (des)acuerdo existentes entre quienes se dedican a estudiar la materia debatida desde las ciencias. Este argumento no es definitorio para el tribunal ni tampoco es utilizado con frecuencia. Las razones son conocidas, en temas difíciles, pueden existir en la comunidad de especialistas fuertes disensos, incluso las cuestiones pueden estar abiertas o no haber sido exploradas en forma suficiente. Por lo demás, tampoco se trata de dar a los y las expertas la última palabra sino tratarlo como un informe, en su caso, o argumento suplementario, pero no definitorio. Dzehtsiarou (2015).

20 Cuántos Estados deben presentar una solución similar para hablar de un consenso, no es claro. A los efectos de este trabajo, no es determinante explorar cómo se llega a determinar el consenso (v. una discusión en WiLDHABER (2013). Aquí interesa el uso del argumento como tal en la justificación de la sentencia.

21 El proceso de comparación implicaría el tratamiento de las siguientes preguntas: a) El problema o cuestión que se discute en el caso, ¿fue tratado en los Estados del Consejo de Europa? b) Si fuere el caso, ¿a qué solución se llegó respecto del problema discutido? c) ¿Cuáles son las similitudes, diferencias, particularidades que presentan cada una de las soluciones? d) ¿Surge de la comparación una suerte de "común denominador"?

e) ¿Se puede, entonces, concluir que existe un consenso sobre la materia jurídica objeto del caso que debe ser resuelto (por ejemplo, en relación con el reconocimiento jurídico del matrimonio entre personas con la misma orientación sexual) o no existe consenso o este está es aún endeble? Estas preguntas están presupuestas en las sentencias que se refieren al matrimonio igualitario bajo el manto del artículo 8, 12 y 14 dela CEDH, ver, por ejemplo, Kopf y Schalck vs. Österreich (2010), Hämäläinen vs. Finlandia (2014); Oliari vs. Italien (2015); Orlandi vs. Italia (2017, párr. 205).

22 Desde hace más de una década los informes con realizados por la División de Investigación y Biblioteca dependiente del Court Registry. En un primer momento, el TEDH se basaba en las referencias comparadas que surgían de los amici curiae o de terceros. DzeHTSIArou (2015, $2-3 ; 86)$. 
o de otros sistemas de protección de derechos humanos como la Corte IDH, la CIDH, el sistema africano de protección. Aquí puede aparecer un ejercicio de determinación de convergencias/divergencias. El resultado de esa comparación puede conformar en caso de convergencia una "tendencia internacional".

\section{a) Dos funciones: una descriptiva y otra normativa. Tres problemas}

La función del consenso es descriptiva, si se trata de la determinación de cómo la cuestión del caso fue resuelta en los ordenamientos jurídicos de la región o en el ámbito internacional. La forma del argumento no incluye hasta aquí ninguna premisa normativa (función 1). Esta función del uso del consenso responde a lo que se llama "consenso fáctico".

La segunda función apunta a satisfacer la pretensión de corrección (función 2). El objetivo del uso del argumento de derecho comparado es considerado como parte de una constelación argumentativa para sostener la mejor interpretación de una norma de derechos humanos o la mejor justificación para la solución de un conflicto entre derechos. Por ejemplo en el caso Atala sobre discriminación por orientación sexual ${ }^{23}$, la Corte IDH utiliza producciones de la ONU y el case law del $\mathrm{TEDH}^{24}$, entre otras, para sostener que la Sra. Atala fue víctima de un trato discriminatorio ${ }^{25}$. La Corte considera entonces el derecho comparado como parte de la interpretación evolutiva con aplicación de la regla de interpretación pro persona (“debe elegirse la alternativa más favorable para la tutela de los derechos protegidos por dicho tratado, según el principio de la norma más favorable al ser humano") y en el marco del objeto y fin de

23 La Sra. Atala se había divorciado en el 2002, tenía a su cargo — de común acuerdo con su excónyuge - el cuidado y tuición de sus tres hijas. En noviembre de 2002, la pareja mujer de la Sra. Atala, la Sra. E. de R., se mudó a la casa de la Sra. Atala, donde también vivían las tres niñas. En enero de 2003 el padre de las niñas solicitó ante sede judicial la tuición sin haber tenido éxito en primera y segunda instancia. En marzo de 2004 la Corte Suprema de Chile revocó la sentencia y otorgó la tuición de las niñas al padre. La Sra. Atala denunció al Estado ante la CIDH alegando que esta acción estatal implicaba una violación al principio de no-discriminación por orientación sexual, a la vida privada y familiar, entre otros.

24 La Corte IDH interpreta que la orientación sexual y la identidad de género son categorías protegidas por la Convención Americana bajo el término "otra condición social" establecido en el artículo 1.1 de la CADH. Caso Atala párr. 87 con referencia a jurisprudencia T.E.D.H, en particular, en el Caso Salgueiro da Silva Mouta vs. Portugal.

25 En especial, se inspiró en el caso "Salgueiro da Silva Mouta vs. Portugal”, en el que el TEDH interpretó que el tribunal interno, al considerar la convivencia del padre con otro varón como tal, asignó a la orientación sexual del peticionario un factor decisivo para el fallo judicial final. Con base en esta jurisprudencia, la Corte IDH tomó como relevante los argumentos expuestos por las autoridades judiciales nacionales, sus conductas, el lenguaje utilizado y el contexto en que se han producido, para concluir que la diferencia de trato se basó en la orientación sexual, s. una discusión de las convergencias/divergencias entre el TEDH y la Corte IDH respecto de esta parte de la sentencia, v. Abrusci (2017). 
la CADH (la protección de los DDHH) ${ }^{26}$. Concluye así que los Estados tienen prohibido discriminar en virtud de la orientación sexual en desmedro de las personas LGBTTTI. Esta parte de la argumentación comprende dos pasos: a) la tendencia internacional (evolución) es identificada (función descriptiva); b) luego, esa tendencia es analizada en relación con las razones que la sustentan y es incluida en la constelación argumentativa que sostiene el resultado de la interpretación evolutiva en la medida en que implica una mejor protección del derecho en juego, que determina que está prohibido discriminar a las personas por su orientación sexual (función normativa, función 2). El uso normativo del argumento de derecho comparado conforma la constelación argumentativa ${ }^{27}$ que busca satisfacer la pretensión de corrección ${ }^{28}$.

El argumento de derecho comparado comprende la descripción de la situación de derecho en otra sociedad o Estado (esto es, un hecho) y determina similitudes, diferencias y particularidades. Sin embargo, lo importante es que esta forma de argumento no solo implica cuestiones de hecho (consenso o disenso fáctico, función 1), sino que incluye "una premisa normativa" que debe ser justificada ${ }^{29}$. El uso del argumento de derecho comparado para la

26 Caso Atala, párr. 84, Clérico (2012), LixinSKI $(2017,70)$ sobre la diferencia entre la Corte IDH y el TEDH en la interpretación evolutiva de los tratados. Mientras que el TEDH apunta con la interpretación evolutiva a actualizar la CEDH para que sea porosa a los cambios en la sociedad, la Corte IDH la utiliza en forma acoplada de manera que promueva el objeto y el propósito de la CADH.

27 CléRICO 2011, 2017. LiXINSIKI $(2017,95)$.

28 La pretensión de corrección implica una afirmación (por ejemplo, la prohibición de trata de personas surge de la interpretación del art. 4 del CEDH aunque no esté expresamente escrita en el enunciado normativo); una garantía de justificabilidad (la CEDH es un instrumento vivo, el objeto y fin de la CEDH es la protección de la dignidad de la persona; la trata de personas toma a las personas como objetos y no como fines en sí mismos, como commodities, esto contradice el objeto y fin del tratado; además, en otros sistemas de protección internacional de DDHH la trata de personas está prohibida en forma absoluta por las mismas razones aquí alegadas) y, por último, incluye la expectativa de que el auditórium de ese sistema debe reconocer esta interpretación como correcta si adopta la perspectiva de la protección internacional de derechos humanos. Para la explicación de la pretensión de corrección reconstruimos la argumentación del TEDH en el caso Rantsev vs. Chipre y Rusia. En relación con el contenido de la pretensión de corrección en general, v. Alexy (1995); SiecKMAnN (2014, 62). A los efectos de este trabajo, alcanza la reconstrucción aquí ensayada, ella demuestra la dimensión normativa de la pretensión (argumentación sobre lo debido, lo prohibido y lo permitido) y la disposición a dar razones normativas ante la pregunta por la justificación de la afirmación.

29 Alexy (1991, 294); Clérico (2017). La forma del argumento de derecho comparado puede ser así precisada:

(1) ya en otro lugar (ámbito internacional, región, Estado), se practicó una determinada solución del problema discutido, (2) esta solución ha permitido una armonización de los dos derechos en conflicto $(\mathrm{F})$,

(3) (F) puede ser justificada con muy buenas razones,

(4) las situaciones, cuestiones normativas, del problema discutido en el caso bajo disputa y las de las adoptadas en otros lugares son similares, y

(5) la solución practicada del problema discutido y su justificación debe ser considerada en la constelación argumentativa que sostiene la justificación del caso. 
satisfacción de la pretensión de corrección (función 2), supone su uso para la consideración de toda la información (función 1) y argumentos relevantes, se relaciona con la pretensión de racionalidad. El problema surge cuando la argumentación se detiene en la descripción (función 1). Un uso correcto del argumento de derecho comparado en la argumentación en derechos humanos debe contener una premisa normativa y su justificación (función 2) (tabla 1).

TABLA 1

\begin{tabular}{|l|l|l|}
\hline \multicolumn{1}{|c|}{ Uso/función } & \multicolumn{1}{|c|}{ Fáctico (descriptivo) } & \multicolumn{1}{|c|}{$\begin{array}{c}\text { Normativa (dar razones para } \\
\text { determinar lo prohibido, } \\
\text { permitido u obligatorio) }\end{array}$} \\
\hline Consenso/tendencia regional & Consenso regional fáctico & Consenso regional normativo \\
\hline $\begin{array}{l}\text { Consenso/tendencia } \\
\text { internacional }\end{array}$ & $\begin{array}{l}\text { Consenso internacional } \\
\text { fáctico }\end{array}$ & Consenso internacional normativo \\
\hline
\end{tabular}

Fuente: elaboración propia.

Las combinaciones entre los diversos usos y funciones posibilitan, por un lado, una reconstrucción crítica de la jurisprudencia del TEDH, cuando utiliza el argumento del derecho comparado como ausencia de "consenso europeo" (tendencia regional) en su función descriptiva (función 1) ${ }^{30}$ para luego reconocer que corresponde al Estado un amplio margen de apreciación para determinar cómo quiere cumplir con las obligaciones que surgen de la Convención. Aquí se vislumbra una especie de (salto o) insuficiencia argumentativa. Por el otro, permite explorar cómo se desempeña el argumento de derecho comparado como tendencia internacional en una constelación de argumentos para justificar la mejor interpretación de las normas en conflicto (pretensión de corrección) ${ }^{31}$. Por último, nos lleva a discutir el uso del argumento del consenso europeo (función 1) para identificar tres problemas argumentativos: el de la identificación del objeto de comparación ${ }^{32}$; el de

30 SјӧноLм $(2018,144)$.

31 Este uso fue abordado en otros trabajos, CLÉRICO (2017).

32 Se trata de todos los problemas relacionados con la determinación del objeto de comparación, de la cuestión del método de comparación, de la determinación e interpretación de las similitudes, diferencias, particularidades que surgen como resultado de la comparación. Asimismo, si como resultado de la comparación surge una convergencia, al respecto ver, DzEHTSIAROU; LUKASHEVICH (2012); WILDHABER (2013). La importancia práctica del problema surge, por ejemplo, en el caso sobre prohibición de uso en público de la burka o niqab en Francia, TEDH en "S.A.S. contra Francia" (2014). En ese caso, el voto de mayoría se pregunta, si la mayor parte de los Estados del Consejo de Europa prohíben llevar la cara totalmente cubierta en público (por ejemplo, por medio del uso de la burka o el niqab). El resultado de esta comparación, según surge de la sentencia, es que solo Francia y Bélgica adoptan una prohibición similar y que en tres países se discute en el ámbito legislativo el tema (en Suiza, en Holanda y en España en forma más acotada en cuanto a la prohibición y en el ámbito de una región). Luego interpreta el TEDH que no existe consenso respecto de la prohibición, entonces le reconoce al Estado un 
la insuficiencia argumentativa y el de la incoherencia ${ }^{33}$. En especial, nos detenemos en el segundo, en este trabajo.

\section{b) Consenso regional como criterio para la determinación del margen de apreciación estatal (MoA)}

En la jurisprudencia del TEDH el argumento de la presencia o ausencia del llamado consenso europeo es utilizado como un criterio $^{34}$ para la determinación del margen de apreciación de los Estados (en adelante, MoA). Según la doctrina del margen ${ }^{35}$, las autoridades nacionales estarían mejor posicionadas que el TEDH, en principio, para realizar el test de la necesidad de la restricción en una sociedad democrática ${ }^{36}$. El TEDH controla ese examen, esto es, si la restricción es necesaria y si está justificada en forma adecuada y suficiente de acuerdo con las particularidades de protección de cada uno de los derechos en juego y a la luz del case law del TEDH ${ }^{37}$. Ese control admite diversas intensidades. Por caso, el TEDH basándose en el "consenso" de la

amplio margen de apreciación (consids. 156, 40). Sin embargo, qué ocurre respecto de todos los demás estados de la región que no consideraron relevante legislar sobre el tema. ¿Por qué no fue considerado en la argumentación del voto mayoritario? El voto disidente en S.A.S. contra Francia levanta el guante. Interpreta que 45 de los 47 Estados del Consejo de Europa no han visto como necesario legislar sobre el uso de la burka o el niqab en público, este resultado implica un indicio de que existe un consenso europeo a favor de la no-prohibición de su uso en público, con lo que concluye - atendiendo a su vez a otras razones - que se debe aplicar un examen de proporcionalidad que examine con intensidad las razones alegadas por el Estado para sostener la restricción (consid. 19 del voto en disidencia). Como se puede apreciar, los dos votos reflejan una discusión sobre el objeto de comparación e interpretación del resultado, ¿qué se compara la prohibición o la no-prohibición? Pero, si del resultado de la comparación surge que en una clara mayoría de Estados no existe la prohibición, entonces la mayoría converge en no limitar la autonomía de las personas, este punto no es trabajado por el voto mayoritario, si por la disidencia. En este sentido, vemos que la mayoría presenta una argumentación débil en relación con el uso del argumento de derecho comparado como expresión de la falta de consenso, SÜNDHOFER $(2015,88)$, KLEINLEIN $(2017,877)$; SJÖHOLM $(2018,145)$, entre otras.

33 Aquí la falta o no de consenso no es utilizada en forma coherente. Por ejemplo, la falta de consenso europeo sobre derechos de las personas trans no fue determinante en el caso Goodwin (2002, párr. 90). Esa inexistencia se contrapuso a la identificación de una tendencia creciente en el ámbito internacional a favor del reconocimiento de los derechos de las personas trans. Sin embargo, en Hämäläinen vs. Finlandia, el TEDH reconoce a los Estados un amplio margen de apreciación. La tendencia internacional en favor de una mayor y mejor protección de los derechos de las personas trans no es tomada en cuenta en la argumentación (párr. 74), como sí ocurrió en el caso Goodwin. Por el contrario, v. el voto en disidencia en el caso Hämäläinen de los jueces Sajó, Keller y Lemmens.

34 El TEDH fue estableciendo los criterios para la determinación del alcance del MoA en el caso, TEDH, Marper vs. Reino Unido (2008, párr. 102); von Hannover vs. Alemania (No. 2, 2012, párr. 107) y Animal Defenders vs. UK $(2013,108)$, entre otros. Cfr. SAUL $(2015,745)$.

35 LegG (2012); Iglesias VIla (2017); Gerards (2018); Gorzoni (2019).

36 Similar o funcional equivalente del test de proporcionalidad, v. entre muchos otros, FøLleSDAL, (2017, 368).

37 Farahat $(2015,320)$; Aldao (2019). 
mayoría de los Estados se siente más legitimado para reducir el margen de apreciación del Estado demandado ${ }^{38}$ y aplicar un examen de las razones estatales bien intensivo. Si no existe el llamado "consenso europeo", entonces es probable que le reconozca un amplio margen de apreciación al Estado demandado y no desarrolle el examen de proporcionalidad e igualdad en su plenitud argumentativa. Por su parte, la academia especializada sostiene que esto se combina con la presunción de convencionalidad ${ }^{39}$. Si hay consenso, la norma atacada se presume in-convencional. El Estado tiene que destruir esa presunción y con razones de mucho peso. A la inversa, la inexistencia de consenso parte de la presunción de convencionalidad y la carga agravada de la argumentación está en cabeza de la afectada (tabla 2).

TABLA 2

\begin{tabular}{|l|l|l|l|}
\hline \multicolumn{1}{|c|}{ Consenso europeo } & \multicolumn{1}{|c|}{$\begin{array}{c}\text { Margen de } \\
\text { apreciación estatal }\end{array}$} & \multicolumn{1}{|c|}{$\begin{array}{c}\text { Presunción de } \\
\text { convencionalidad }\end{array}$} & $\begin{array}{c}\text { Examen de } \\
\text { proporcionalidad, } \\
\text { examen de igualdad }\end{array}$ \\
\hline Existencia & Restringido & $\begin{array}{l}\text { La norma atacada } \\
\text { se presume in- } \\
\text { convencional }\end{array}$ & Intensivo \\
\hline Inexistencia & $\begin{array}{l}\text { Amplio a favor del } \\
\text { Estado }\end{array}$ & $\begin{array}{l}\text { La norma se presume } \\
\text { convencional }\end{array}$ & Leve \\
\hline
\end{tabular}

Fuente: elaboración propia.

Este juego de relaciones no siempre es claro. En algunos casos parece usarlo de forma estratégica ocultando los criterios de aplicación. Razón por la que ha sido objeto de análisis y crítica de la academia ${ }^{40}$. Por un lado, implicaría ir en contra de uno de los fines básicos de la Convención referidos a establecer estándares universales y de ser el TEDH guardián de su cumplimiento. Asimismo, debilitaría la llamada interpretación autónoma del TEDH; es decir, el principio de que la CEDH tiene un significado no necesariamente atado a los significados de los Estados en el orden interno. Por el otro lado, se lo

38 Este no fue el caso en el caso A, B \& C v. Ireland, TEDH 17/12/2010, referido a la pregunta sobre la compatibilidad de las restricciones extremas al aborto en Irlanda con la Convención. El TEDH concedió que existe un consenso europeo sobre causales de permisión de aborto más amplias a las muy restrictivas admitidas por Irlanda (235), por lo que era de esperar que no le concediera un amplio margen de apreciación al Estado demandado. Sin embargo, el TEDH sostuvo en este caso que el consenso europeo (mayoría sustancial) en la materia no limitaba el margen de apreciación del Estado, porque los supuestos restrictivos de aborto se basaba en una perspectiva moral profunda ("profound moral view") de la gente en Irlanda. Esto generó la crítica del voto en disidencia de los jueces Rozakis, Tulkens, Fura, Hirvelä, Malinverni y Poalelungi; v. De Londras; Dzehtsiarou (2013:62); SJöHolm (2018, 146); KLeinlein (2017); Álvarez (2017).

39 Dzehtsiaurou (2015); S S̈̈нolm $(2018,142)$. En el intermedio, sobre el "evolving consensus" (Bamforth, 2016, 133) otorgando a los Estados un amplio margen en el timing respecto de cuándo incluir, por ejemplo, reconocimiento al matrimonio igualitario en la legislación interna.

40 Benvenisti (1999, 852); Letsas (2004, 279). Cfr. de Londras; Dzehtsiarou (2013). 
critica, porque no surge claro de la jurisprudencia del tribunal determinar qué se desprende de esta identificación del estado de la cuestión jurídica ${ }^{41}$. ¿Finaliza ahí?, es decir, ¿es mera información? (una especie de consenso fáctico, función 1). $\mathrm{O}$ ¿es parte de una constelación argumentativa donde el resultado de la comparación es solo un eslabón para satisfacer la pretensión de corrección (función 2)? La reconstrucción de la jurisprudencia no arroja una única respuesta.

\section{c) Escenarios y complejidades del uso del consenso europeo}

Londras y Dzehtsiarou (2013) identifican tres usos diferentes del consenso europeo para la determinación del MoA, al que se le puede agregar un cuarto $^{42}$. Con esto alcanza para sostener la complejidad en el uso del argumento del consenso europeo:

1) No existe consenso europeo, es decir, con la consecuencia de que la norma o práctica atacada es compatible con la convención, salvo que la norma tenga una justificación desproporcionada en forma evidente. El tribunal reconoce al Estado un amplio margen de apreciación. Esto ocurre en los casos sobre matrimonio para personas del mismo $\operatorname{sexo}^{43}$. Llevadas estas consideraciones al extremo, esto implica sostener que un hecho (la inexistencia de consenso fáctico acerca de cómo reconocer y regular el matrimonio igualitario) es utilizado para sostener un control leve de la justificación material alegada por el Estado respecto de la intervención del derecho a la vida privada, a la familia y a la no-discriminación de las personas del mismo sexo. Aquí ocurre un salto argumentativo, nada más ni nada menos que en materia de evaluación de una restricción a un derecho y respecto de un colectivo de personas que históricamente ha sido discriminado y que las consecuencias de esa discriminación persisten en desmedro del goce efectivo de sus derechos hasta la actualidad.

2) No existe consenso europeo, con la consecuencia de que la justificación de la norma atacada debe seguir siendo evaluada en cuanto a posibles razones materiales que alegue el Estado. Vale como ejemplo el caso "Hirst vs. Reino Unido" (2005) sobre derechos políticos de las personas presas. La legislación británica impone una prohibición general de sufragio a los presos condenados a prisión o reclusión, el TEDH resolvió que esto viola los derechos políticos de las personas - art. 3 del Protocolo $n^{\circ} 1$ de la CEDH - . El TEDH establece que el Reino Unido no es el único Estado que establece tal prohibición. Agrega

41 Wildhaber $(2013,249)$ : el TEDH trataría de mantener una concepción lo suficientemente "fuzzy" para evitar las consecuencias de inclinarse por una en particular.

42 Corresponde con el uso que se presenta en 2).

43 V., Shalck y Kopf vs. Austria; Hämäläinen vs. Finlandia; Oliari vs. Italien. Cfr. HeLfER; VOETEN (2014). 
que si bien no se puede establecer un "common European approach" para el tratamiento de la cuestión del voto de los detenidos, porque existe una variedad ${ }^{44}$ en disputa, esto no sería determinante para resolver el caso ${ }^{45}$. De ahí se sigue que para el tribunal, a pesar de que el margen de apreciación del Estado es amplio, no es omnicomprensivo. Se examinan las razones estatales que pretenden justificar la restricción.

3) Existe un consenso europeo identificable a favor de la norma o práctica estatal atacada. La consecuencia es entonces que la norma atacada es compatible con la CEDH. En el fallo de Sala del TEDH en "Stoll vs. Suiza", Suiza fue condenada por haber impuesto una multa de 800 francos a un periodista por la publicación de material confidencial clasificado referido al entonces embajador de Suiza en los Estados Unidos, en relación con una disputa sobre el patrimonio judío no reclamado. La Gran Cámara del TEDH revocó el fallo, decidió que no había violación. Entre otros argumentos, sostuvo que el art. 293 del Código Penal Suizo (StGB) es similar a otras normas de los Estados de la región europea: "a consensus appears to exist among the member States of the Council of Europe on the need for appropriate criminal sanctions to prevent the disclosure of certain confidential items of information" ${ }^{46}$. Sin embargo, el argumento del consenso europeo no fue el único considerado para examinar la justificación de la restricción. El TEDH consideró, asimismo, el monto leve de la sanción y el hecho de que el periodista hubiera podido expresar su opinión. Más allá de la decisión final del caso, lo que importa a los efectos de este trabajo es que la identificación de un consenso fáctico sobre el estado de cosas jurídico en la región no implicó detener el examen de la justificación estatal. El argumento del consenso es aquí un paso más en la constelación argumentativa.

4) Existe un consenso europeo identificable en contra de la norma atacada. Por regla se presume que la norma atacada es contraria a la CEDH y el Estado demandado ha violado la convención ${ }^{47}$. En estos casos, el tribunal examina las razones alegadas por el Estado en forma bien intensiva, con lo que se restringe muy considerablemente el margen de apreciación de los Estados. En el conocido caso "Dudgeon vs. Reino Unido", el argumento del consenso europeo a favor de la descriminalización de las prácticas homosexuales fue relevante para justificar la sentencia condenatoria para el Reino Unido por las leyes que criminalizaban las prácticas sexuales entre homosexuales en Irlanda

44 TEDH, Hirst c. Reino Unido, párr. 33.

45 Id.,párr. 33: "[...] Moreover, and even if no common European approach to the problem can be discerned, this cannot in itself be determinative of the issue."

46 TEDH "Stoll vs. Suiza" (2007), párrs. 155, 157, 44.

47 Por ejemplo, el TEDH identificó una violación a la CEDH basado en la existencia de consenso europeo sobre la materia en casos sobre el derecho al nombre, la no-discriminación de niños nacidos fuera del matrimonio, objeción de conciencia y violación, entre otros, v. Dzehtsiarou (2015). 
del Norte. Luego de un análisis intensivo de la medida estatal concluyó que se violó el derecho a la vida privada de las personas ${ }^{48}$.

Los escenarios arriba presentados demuestran la diversidad en el uso del consenso europeo. A la luz de la satisfacción de la pretensión de corrección (función 2), en especial, resulta problemático el escenario $\mathrm{n} .^{\circ} 1$. Veamos.

\section{d) Argumentatio interrupta}

En principio no es problemático que un tribunal tenga en cuenta la normativa y las prácticas de los Estados en la cuestión debatida (función 1). Considerar esas normas, esas interpretaciones, para compararlas y discutirlas en la argumentación (función 2), responde al mandato de saturar la consideración de todos los argumentos relevantes.

El TEDH identificó pisos europeos comunes a favor de la despenalización de las prácticas sexuales consentidas entre personas homosexuales y a favor de la no-exclusión de los empleos a las personas por su orientación sexual. Sin embargo, no ocurre lo mismo en el caso de matrimonio entre personas del mismo sexo y en parte de la materia adopción. Aquí aparecen los déficits argumentativos cuando el escrutinio se detiene bajo la alegación de que no existe consenso fáctico en estas materias en la región y que entonces cabe al Estado reconocer un amplio margen de apreciación. Se trata del problema de la insuficiencia argumentativa.

Sin embargo, se debería justificar por qué, por ejemplo, la falta de convergencia, supone razones que sostienen (o no) la distinción. Se requiere argumentación material. Por el contrario, de una descripción se salta a sostener que no es necesario realizar un examen de igualdad de la medida estatal atacada. El problema de la insuficiencia argumentativa se encuentra en del voto mayoritario en el citado caso Kopf y Schalck vs. Austria (2010): "[...] there is no European consensus regarding same-sex marriage. [...] there is not yet a majority of States [...] The area in question must therefore still be regarded as one of evolving rights with no established consensus, [...]". Sostiene que como no existe consenso sobre el estado de cosas jurídico en la región, se debe reconocer a los Estados un "timing" para la introducción de los cambios legales ${ }^{49}$. Detiene la argumentación justo en casos en los que se

48 Edel (2015); JoHNSON (2018).

49 Párr. 105. Muy probablemente las críticas al uso del argumento de la falta de consenso europeo como criterio aislado para ampliar el margen de apreciación del Estado supone una crítica a la "concepción estatista de la subsidiariedad" (“[...] una visión de mínimos, claramente pactados, y con un control externo deferente con el criterio nacional"). Por lo demás, Marisa Iglesias (2017) propone una concepción cooperativa de la subsidiaridad, que implica un enfoque racionalizado del MoA que tiene en cuenta: a) el tipo y contenido de los derechos en juego y b) los tests de idoneidad y necesidad de la medida impugnada. En cada uno de los pasos de este examen advierte que se deben incluir consideraciones relacionadas con el "sentido y dinámica 
alega afectado, es el libre desarrollo de la personalidad, de la autonomía en cuestiones de orientación sexual o identidad de género. Lo que se ataca como discriminatorio son las tradiciones que sostienen la exclusión de las personas por no responder sus orientaciones a la de la mayoría. Por el otro lado, el TEDH contesta con una descripción de la falta de consenso, con la reiteración de que se trata de una cuestión referida a la moral o las tradiciones (sensitive moral or ethical issues $)^{50}$ - justamente lo que se ataca por discriminatorias $-{ }^{51}$. Este criterio se reitera en Oliari vs. Italia (2014) en la parte referida a matrimonio igualitario ${ }^{52}$. Se deniega a los afectados el tratamiento de la cuestión de discriminación ${ }^{53}$ (art. 12 en combinación con el art. 14) ${ }^{54}$ : el tribunal les niega el derecho a recibir una justificación suficiente. Responder que no se escrutará esa base bajo el manto de la falta de consenso europeo, implica un fuerte déficit argumentativo ${ }^{55}$ en materia de derechos humanos.

general del sistema europeo de protección de derechos humanos", entre otras, el estado del consenso europeo en la materia debatida. Para IgLesias, "la relevancia del argumento dependería de un balance entre razones de seguridad jurídica y consideraciones sustantivas en un ajuste mutuo que favorezca la consolidación de derechos humanos". En su concepción incrementalista de los derechos, el uso de la falta de consenso para ampliar el MoA del estado resultaría excluido "si ello acabara redundando en una paulatina disminución del estándar de protección en la región". Sin embargo, dejamos pendiente una discusión pormenorizada de la función consenso europeo en la teoría de Marisa Iglesias del MoA, en tanto por ahora no forma parte central de su propuesta.

50 SЈöHOLm $(2018,154)$ advierte que el TEDH estaría otorgando piedra libre a los estados para defender o introducir leyes restrictivas de género para preservar las costumbres sociales.

51 "In the absence of a European consensus and taking into account that the case at stake undoubtedly raises sensitive moral or ethical issues, the Court considers that the margin of appreciation to be afforded to the respondent State must still be a wide one." TEDH, "Hämäläinen vs. Finnlandia" (2014), párr. 75; "Kopf und Shalk vs. Austria”, cfr. Oliari vs. Italia, párr. 163. LETSAS, G. (2009, 11, 81, 84; 91-95; 120-126): "lack of consensus amongst contracting states on whether same-sex partnerships should be recognised by law should be as irrelevant as a prejudiced moral climate towards homosexuals in the respondent state".

52 En OLIARI (párrs. 164-187), el TEDH condena al Estado por violación del derecho a la protección de la vida privada y la familia, ya que Italia no preveía un legal framework suficiente para satisfacer las "core needs relevant to a couple in a stable committed relationship". Agregó que la union civil o similar "would be the most appropriate way for same-sex couples like the applicants to have their relationship legally recognized. V. Ragione; VOLPE (2016).

53 TEDH, "Oliari vs. Italia", párr. 191-192: “[...] while it is true that some Contracting States have extended marriage to same-sex partners, Article 12 cannot be construed as imposing an obligation on the Contracting States to grant access to marriage to same-sex couples. [...] The Court notes that despite the gradual evolution of States on the matter (today there are eleven $\mathrm{CoE}$ states that have recognised same-sex marriage) the findings reached in the cases mentioned above [Schalk a. Kopf vs. Austria; Hämäläinen vs. Finland] remain pertinent. In consequence the Court reiterates that Article 12 of the Convention does not impose an obligation on the respondent Government to grant a same-sex couple like the applicants access to marriage." V. advierte que esta parte del pronunciamiento en Oliari implicaría incluso un retroceso en comparación con Schalk y Kopf vs. Austria.

54 TEDH, Oliari vs. Italia, párr. 193.

55 Una crítica similar pero para el case law referido a libertad religiosa (art. 9) y, en especial, al caso Lautsi vs. Italia (GC), v. Zucca, 2013, 229. 


\section{e) La Corte IDH niega tres veces el uso del argumento de la falta de consenso regional. Divergencia con el TEDH}

Dado el fenómeno de diálogo ${ }^{56}$ entre ambos tribunales, podría ser probable que la Corte IDH en algunos casos se sienta tentada de copiar esta relación argumentativa entre examen de proporcionalidad/igualdad, margen de apreciación ${ }^{57}$ y falta de consenso regional como se desarrolla en la jurisprudencia del $\mathrm{TEDH}^{58}$. Tres son las decisiones de la Corte IDH sobre orientación sexual que importan al respecto: Atala vs. Chile; Duque vs. Colombia y la Opinión Consultiva 24.

La Corte IDH dio pruebas de no haber sucumbido frente a la primera tentación presentada, en este caso, por el Estado en Atala ${ }^{59}$. En el caso, la Corte IDH condenó al Estado por el trato discriminatorio y la interferencia arbitraria en la autonomía y protección familiar de Karen Atala Riffo, debido a su orientación sexual, en el proceso judicial que resultó en el retiro de la custodia de sus hijas M., V. y R. ${ }^{60}$ El Estado alegaba que para el tiempo que la Corte Suprema chilena dictó sentencia no había consenso en la región sobre la prohibición de discriminación por orientación sexual. La Corte IDH rechaza en forma expresa el uso de la falta de consenso regional como criterio para detener la argumentación:

En lo que respecta al argumento del Estado de que para la fecha de emisión de la sentencia de la Corte Suprema no habría existido un consenso respecto a la orientación sexual como categoría prohibida de discriminación, la Corte resalta que la presunta falta de un consenso al interior de algunos países sobre el respeto pleno por los derechos de las minorías sexuales no puede ser considerado como un argumento válido para negarles o restringirles sus derechos humanos o para perpetuar y reproducir la discriminación histórica y estructural que estas minorías han sufrido. El hecho de que ésta pudiera ser materia controversial en algunos sectores y países, y que no sea necesariamente materia de consenso no puede conducir al Tribunal a abstenerse de decidir, pues al hacerlo debe remitirse única

56 Voeten (2010, 563); PARRa Vera (2016) muestra referencias cruzadas entre el TEDH y la Corte IDH.

57 Sobre la doctrina del margen de apreciación en el contexto interamericano: AcosTA Alvarado (2011), Aldao (2019), Barbosa Delgado (2011), Benavides Casal (2009), Contesse (2016), Contreras (2009), Pérez (2017), Sánchez Molina (2015), Tsereli (2016).

58 En este trabajo analizo la constelación de casos referidos a orientación sexual. Por ello, dejo de lado la utilización del argumento del consenso en el caso Artavia Murillo vs. Costa Rica sobre reproducción asistida (2012: 245). Cfr. Føllesdal (2017, 369); LiXINSKI (2017, 79); CLÉrico (2012).

59 El caso llegó como denuncia a la Comisión Interamericana de Derechos Humanos (en adelante, $\mathrm{CIDH}$ ) fruto de un reclamo presentado el 24 de noviembre de 2004 por la señora Karen Atala Riffo; y, a la Corte IDH luego de haber pasado sin éxito por una instancia de solución amistosa en el ámbito de la CIDH.

60 V. hechos en nota 23 de este trabajo. 
y exclusivamente a las estipulaciones de las obligaciones internacionales contraídas por decisión soberana de los Estados a través de la Convención Americana. ${ }^{61}$

En Ángel Alberto Duque vs. Colombia, la Corte IDH condena al Estado por la violación al derecho a la igualdad ante la ley y a la no discriminación en perjuicio de Duque, por no haberle permitido acceder en condiciones de igualdad a la pensión de sobrevivencia, luego de la defunción de su pareja por tratarse de una pareja del mismo sexo. En aquel momento, la normatividad interna colombiana disponía que únicamente el cónyuge o el compañero o compañera permanente sobreviviente de sexo diferente al del causante tenían derecho a la pensión ${ }^{62}$. La Corte IDH reitera en Duque que la inexistencia "the regional consensus" no implica obstáculo para decidir la cuestión ${ }^{63}$ ni para realizar un examen intensivo de igualdad. Así la Corte IDH concluyó que "[...] el Estado no presentó una justificación objetiva y razonable para que exista una restricción en el acceso a una pensión de sobrevivencia basada en la orientación sexual" ${ }^{64}$. En la Opinión Consultiva Nro. 24 (2018) sobre orientación sexual e identidad de género, la Corte $\mathrm{IDH}^{65}$ reiteró, en atención a "su jurisprudencia constante" "66, "[...] que la presunta falta de un consenso al interior de algunos países respecto del respeto pleno por los derechos de las minorías sexuales no puede ser considerado como un argumento válido para negarles o restringirles sus derechos humanos o para perpetuar y reproducir la discriminación histórica y estructural que estas minorías han sufrido" ${ }^{67}$.En especial, lo que interesa a los efectos de este trabajo (función 2) es que la falta de consenso regional no fue una excusa para interrumpir la argumentación y evadir realizar un examen de igualdad ${ }^{68}$. La Corte IDH respondió así con muy buenas armas argumentativas a este embate. Parra Vera y Huber (2012) sintetizan el estándar exigido bajo el lema "una argumentación lo más rigurosa y exhaustiva posible". La Corte IDH no evade justificar por qué no debe reconocer al Estado un margen de apreciación y por qué la falta de consenso sobre la materia no puede alegarse con éxito para evadir el cumplimiento de la obligación de no-discriminación en perjuicio del colectivo LGBTTI: No hay margen de apreciación de los Estados en el caso (aunque no haya consenso en las prácticas de los Estados) porque: a) la orientación sexual de las per-

61 Corte IDH, Atala Riffo y niñas v. Chile, párr. 92.

62 Corte IDH, Duque v. Colombia, párr. 104. Clérico $(2019,1)$.

63 Id., párr. 92.

64 Id., párr. 124 y 79. Clérico (2019).

65 Corte IDH, "identidad de género, e igualdad o no discriminación a parejas del mismo sexo", 2018.

66 Corte IDH, oC Nro. 24, párr. 219, 83; con referencias a Corte IDH, casos Atala Riffo, párr. 92, Duque vs. Colombia, párr. 123, y Caso Flor Freire vs. Ecuador, párr. 124.

67 Corte IDH, oc Nro. 24, párr. 83; 219.

68 Id., párr. 219. 
sonas es una cuestión central de la construcción de la identidad ${ }^{69}$; b) por el ejercicio del derecho a la construcción de la identidad desde orientaciones sexuales que no encajan con la dominante, las personas del colectivo LGBTTI han sido discriminadas histórica y estructuralmente ${ }^{70}$ y las consecuencias de esas prácticas persisten en la actualidad, incluso bajo el uso de estereoti$\left.\operatorname{pos}^{71} ; \mathrm{c}\right)$ el colectivo LGBTTI no se encuentra en igualdad de condiciones para desterrar las prácticas discriminatorias en el ámbito legislativo, judicial, laboral, entre otros.

III. LA COMUNIDAD DE HABLA DEL TEDH Y LA

DE LA CORTE IDH. DIVERGENCIAS

Existen diversas hipótesis que tratan de explicar esta diferencia de enfoque en el uso del argumento de la falta de consenso en la adjudicación. La más extendida sostiene que la divergencia está estrechamente relacionada con el uso que el TEDH realiza del margin of appreciation ${ }^{72}$, otra se refiere al énfasis puesto en el giro consensualista del TEDH; por último, en este texto agregamos otra: las dos Cortes difieren en cuanto a sus audiencias, sus comunidades de habla.

\section{a) La divergencia en el uso del MoA}

En los casos de matrimonio igualitario, hasta tanto no haya consenso, el TEDH reconoce un amplio margen de apreciación de los Estados. En cambio, la Corte IDH hace caso omiso a la falta de consenso y es conocido que en general no ha abrazado la doctrina del margen de apreciación estatal y menos aún con la euforia con que lo ha hecho el TEDH. La Corte IDH podría decidir el caso sobre matrimonio igualitario libre de ataduras, sin importar la inexistencia de consenso regional, en contraste con la posición del TEDH. En suma, dos perfiles diferentes de cortes. Por un lado, la Corte IDH sin cronometraje demandando razones ya; del otro lado, el TEDH en actitud tiempista ${ }^{73}$ hasta tanto no haya consenso fáctico en la materia (no escrutará con minucia las razones estatales ${ }^{74}$ por lo menos en esta línea de casos y en el "mientras tanto").

69 Caso Atala párr. 57.

70 Id., párr. 267.

71 Caso Atala, párr. 92.

72 Burgorgue Larsen $(2017,408)$.

73 AbRUSCi $(2017,256)$. Incluso, literatura especializada que justifica el uso de la falta de consenso europeo incluso aplicado en referencia a "derechos de las minorías" en el contexto europeo, rechaza expresamente su transferencia a otros sistemas de protección regional de derechos humanos porque en determinadas circunstancias puede justificar enfoques restrictivos o conservadores de derechos humanos, Dzehtsiarou $(2015,128)$; cfr. Brems; Desmet $(2017,68)$.

74 Más allá del caso law sobre matrimonio igualitario, el TEDH reconoció amplio margen de apreciación basado en la falta de consenso europeo y no identificó violación a los derechos en 


\section{b) La divergencia en relación con la preocupación del TEDH por la búsqueda del consenso estatal}

De alguna manera, conectada con esta línea, otra de las hipótesis sostiene que el TEDH tendría un enfoque más consensualista estatal por contraposición a uno universalista de la Corte $\mathrm{IDH}^{75}$. La primera preocupación para el TEDH parece ser la legitimidad frente a los Estados. Por el contrario, la Corte IDH estaría preocupada en su legitimidad frente al mundo; a pesar de que esta última estaría recibiendo críticas más severas que el TEDH desde el banquillo de los Estados de las respectivas regiones ${ }^{76}$. O en términos más radicalizados, Brems y Timmer entienden que el TEDH guardaría una actitud de prudencia en clara contraposición con la Corte IDH, que se perfila como la "hija de todas las revoluciones". Mientras que el TEDH estaría preocupado en medir las reacciones políticas que causarían sus pronunciamientos, lo que lo llevaría a sostener un enfoque incrementalista condicionado ${ }^{77}$ de los derechos frente a un enfoque radical. Por el contrario, la Corte IDH se arriesgaría a dar "grandes pasos" en vez de pequeños en protección de los derechos humanos, no se acobardaría cuando tiene que usar "strong language" o se requieren "interpretaciones muy innovadoras" 78 .

\section{c) Audiencias divergentes}

Aún más, por nuestra parte agregamos que la divergencia en los enfoques del TEDH y de la Corte IDH debe ser también explorada en relación con la pregunta acerca de quiénes deben conformar la/s comunidad/es de habla de las cortes regionales. El TEDH parece dar primacía frente a cuestiones sensibles a la comunidad de estados de la región. La deferencia hacia los Estados basada en la falta de consenso europeo en los Estados de la región, implica la indiferencia argumentativa del TEDH respeto de la posición de las poblaciones o grupos en situación de desventaja estructural ${ }^{79}$. La Corte IDH parece estar

cuestión en los casos sobre: regulación de la reproducción asistida, uso de símbolos religiosos, en algunos casos sobre aborto, sobre los efectos legales del cambio de género, eutanasia, y en algunos casos sobre adopción.

75 SјӧHOLM 2018, 154.

76 LIXINSIKI $(2017,74,95)$ : “The IACtHR's primary commitment is still to the defense of human rights in the region, in spite of States Parties."

77 En otro trabajo sostuvimos (CLÉRICO, 2019), que esta diferencia en el enfoque normativo, tiene claras consecuencias en los hechos para el goce efectivo de los derechos. Estudios empíricos demuestran que el TEDH acepta una demanda en favor de los derechos de las personas del LGBTI luego de haber rechazado varios. Por eso fue caracterizado como un "slow adopter" (Johnson, 2018). Por el contrario, la Corte IDH sería una speed adopter. Para el TEDH la falta de consenso regional fáctico es el freno. Para la Corte IDH el examen de igualdad es el acelerador.

78 BREMS/TIMMER, 2016, 6.

79 LANDFRIED: 2017; AldAO (2018); SJÖHOLM (2018). 
concibiendo una comunidad de habla ampliada, no son solo los Estados de la región ${ }^{80}$, sino fundamentalmente las y los afectados ${ }^{81}$, las organizaciones de DDHH y las audiencias ampliadas que se interesan por las razones.

\section{CONCLUSIONES}

En este trabajo sostuvimos dos perfiles de Cortes regionales de Derechos Humanos. El camino argumentativo no fue en general ni en abstracto. Para ello propusimos detenernos en analizar críticamente cómo ambas Cortes utilizan el argumento de la falta de consenso regional en la justificación de la sentencia. Esto nos permitió enfatizar dos cosas. Por un lado, visibilizamos las complejidades del argumento de la falta de consenso europeo. Estas complejidades no son tematizadas por los Estados y la academia que propone su transferencia al contexto interamericano. Para identificar estas complejidades, distinguimos dos significados de "consenso" y dos funciones con las que va emparentado el argumento. Para ello, propusimos re-visitar la estructura del argumento de derecho comparado que es el motor del argumento del consenso europeo. A su vez, este análisis nos permitió identificar tres problemas que plantea el uso del argumento del consenso europeo: el de la insuficiencia argumentativa, el de la identificación del objeto de comparación y el de la coherencia de su uso.

Nos detuvimos en el problema de la insuficiencia argumentativa, parte central de la tesis que atraviesa este trabajo. Este nos permitió determinar a su vez la divergencia entre el TEDH y la Corte IDH. En temas que el TEDH define como moralmente "sensibles" como matrimonio entre personas del mismo sexo y en parte en adopción, ante la falta de consenso de los Estados europeos la respuesta del tribunal es la de la tiempista, des-acelera (Shalck) o interrumpe (Oliari). Aunque, por supuesto, por otro lado, las y los afectados cuenten con muy buenas razones para sostener la discriminación y para que sean escuchadas efectivamente sus voces desde las pluralidades. En cambio, la Corte IDH sostiene, en lo que llama una jurisprudencia "consolidada", otro enfoque. La falta de consenso no implica desacelerar la acometida deliberativa contra la alegada discriminación. Exige al Estado "una argumentación lo más rigurosa y exhaustiva posible" ${ }^{82}$. No evade justificar por qué no debe reconocer al Estado un margen de apreciación y por qué la falta de consenso sobre la materia no puede alegarse con éxito para evadir el cumplimiento

80 Cfr. Neumann $(2008,115)$ quien parece reducirla a "the regional community of states".

81 V. TRACY $(2017,19,21)$, sosteniendo la necesidad de que el Sistema interamericano debería ser más curious para comprender mejor "what, who and where it does not know yet in the region"; $y$ "it is not simply that the IAHRS should take note of national and regional practices, even if it ultimately rejects them, it must ask the right questions about the Americas."

82 PARRA Vera; Huber (2012). 
de la obligación de no-discriminación en perjuicio del colectivo LGBTTI $^{83}$. Por último, analizamos la divergencia en el uso de la ausencia de consenso regional por las dos Cortes en materia de "moral social". Este análisis puso el foco en la función de las Cortes regionales de derechos humanos como foros de reconocimiento y discusión de las voces que son ninguneadas o invisibilizadas en los órdenes internos ya que no se encuentran en igualdad de armas en el debate y definición de las acciones, omisiones e insuficiencias estatales que las afectan ${ }^{84}$. Mientras que el TEDH se perfila como una Corte preocupada por los estados de la región como interlocutores, la Corte IDH sigue siendo una Corte con tendencia universalista ${ }^{85}$.

\section{REFERENCIAS}

Abramovich, Víctor. Autonomía y subsidiariedad: el Sistema Interamericano de Derechos Humanos frente a los sistemas de justicia nacionales. En Rodríguez Garavito, César (coord.). El derecho en América Latina: un mapa para el pensamiento, Ed. Siglo XXI, Buenos Aires, 2011, 211-230.

Abrusci, Elena. A Tale of Convergence? Discrimination based on Sexual Orientation in Regional Human Rights Bodies and the Human Rights Committee. Nordic Journal of Human Rights, 35:3, 2017: 240-257.

Acosta Alvarado, Paola Andrea. El margen de apreciación en el sistema interamericano de derechos humanos: proyecciones regionales y nacionales. Instituto de Investigaciones Jurídicas, 2012.

Aldao, Martín. Entre la deferencia y la indiferencia: margen de apreciación, democracia y situaciones de vulnerabilidad en la jurisprudencia del Tribunal de Derechos Humanos. Revista Derecho del Estado, 44, agosto, 2019: 31-55.

Aldao, Martín; Clérico, Laura y Ronconi, Liliana. A Multidimensional Approach to Equality in the Inter-American Context: Redistribution, Recognition, and Participatory Parity. En v. Bogdandy/Ferrer Mac-Gregor/Morales Antoniazzi/ Piovesan (eds.), Constitutionalism in Latin America, oup, Oxford, 2017.

Alexy, RoBert. Theorie der juristischen Argumentation, Suhrkamp, Frankfurt/Main, 1991.

Alexy, Robert. Teoría del discurso y derechos humanos. Ed. Univ. Externado, 1995.

Álvarez, Silvina. "A, B y C v. Irlanda: el derecho al aborto en Europa", Discusiones, 2017: 133-166.

83 Caso Atala, párr. 57.

84 Dondoli $(2018,14)$; LANDFRIED $(2017,382)$ advierte los jueces que se dejan llevar por métodos políticos, terminarían protegiendo finalmente a las relaciones de poder político existentes en el orden interno y no a los derechos humanos. Se pierde así la función de "institución de supervisión".

85 Brems/Timmer $(2016,6)$; SJöHolm $(2018,154)$; Clérico $(2019,34)$. 
Arai-Takahaschi, Yutaka. The margin of appreciation doctrine: a theoretical analysis of Strasbourg's variable geometry. En Føllesdal /Peters/Ulfstein, (eds.), cup, Cambridge, 2013: 62-105.

Arnardóttir, OddnÝ Muöll. Res Interpretata, Erga Omnes Effect and the Role of the Margin of Appreciation in Giving Domestic Effect to the Judgments of the European Court of Human Rights. European Journal of International Law, Vol. 28, n. ${ }^{\circ}$ 3, Nov., 2017: 819-843.

Bamforth, Nicholas. Social Sensitivity, Consensus, and the Margin of Appreciation. En Agha, Petr (ed.) Human Rights between Law and Politics: The Margin of Appreciation in Post-National Contexts, Hart, 2017.

Barbosa Delgado, F. R. Los límites a la doctrina del margen nacional de apreciación en el Tribunal Europeo y la Corte Interamericana de Derechos Humanos: intervención judicial en torno a ciertos derechos de las minorías étnicas y culturales. Revista Derecho del Estado, n. ${ }^{\circ}$ 26, 2011: 107-135.

Benavides Casals, M. A. El consenso y el margen de apreciación en la protección de los derechos humanos. Ius et Praxis, n. ${ }^{\circ}$ 1, 2009: 295-310.

Benvenisti, E. Margin of Appreciation, Consensus, and Universal Standards. Journal of International Law and Politics, Vol. 31, No. 4, 1999.

Bertoni, EduARDo. The IASHR and the (actual?) lack of regional support. SELA, 2017.

BREMS, EVA y DeSMET, ElLEN. Integrated human rights in practice: rewriting human rights decisions, Northampton, MA: Edward Elgar Pub, 2017.

Brems, Eva y Timmer, Alexandra. Stereotypes and human rights law. Intersentia, 2016.

Burgorgue-Larsen, Laurence. "Decompartmentalization": The key technique for interpreting regional human rights treaties." ICON 16.1, 2018: 187-213.

Burgorgue-Larssen, Laurence, The Added Value of the Inter- American Human Rights System: Comparative Thoughts. En v. Bogdandy/Ferrer Mac-Gregor/Morales Antoniazzi/ Piovesan (eds.), Transformative Constitutionalism in Latin America, Oxford, oup, 2017.

Clérico, LaURa. Discriminación por orientación sexual y derechos de la seguridad social en la jurisprudencia de la Corte Interamericana de Derechos Humanos (Corte IDH) y del Tribunal Europeo de Derechos Humanos (TEDH). Revista de la Facultad de Derecho, Montevideo (47), 2019: 1-34. https://revista.fder.edu.uy/index.php/rfd/article/ view/673/1200

Clérico, Laura y Aldao, Martín. Límites del margen de apreciación desde la perspectiva de género en intersección con pobreza. Revista del Centro de Estudios Constitucionales, $\mathrm{n} .{ }^{\circ}$ 6, 2018.

Clérico, Laura. La enunciación del margen de apreciación: Fontevecchia 2017 desde los márgenes. Revista Derechos en Acción, 2018.

Clérico, Laura. Zur Struktur des Arguments des vergleichenden Rechts in der menschenrechtlichen Argumentation. En Martin Borowski, Stanley Paulson y Jan Sieckmann (Eds.), Rechtsphilosophie und Grundrechtstheorie. Das System Robert Alexys, Editorial 
Mohr/Siebeck (Tübingen), 2017. [Clérico, L. Sobre el argumento de derecho comparado y la argumentación jurídica. En: J. Aguiló Regla, P. Grández Castro (eds.), Sobre el Razonamiento Judicial. Una discusión con Manuel Atienza, Lima: Palestra, 127-151].

Clérico, Laura. Impacto del caso Atala: posibilidades y perspectivas. En v. Bogdandy/ Pióvesan/Morales (eds.), Igualdad y orientación sexual. El caso Atala de la Corte Interamericana de Derechos Humanos y su potencial, Ed. Porrúa, México, 2012.

Coddou, Alberto. A Transformative Approach to Anti-Discrimination Law in Latin America. Diss. University College London, 2018.

Coddou, Alberto. Atala: a landmark in transformative approaches to anti-discrimination law in Latin America. En Fernández, K (ed.), Chile and the Inter-American Human Rights System, Londres: Institute for the Study of the Americas, 2017.

Contesse, Jorge. Conservative Governments and Latin America's Human Rights Landscape. AJIL Unbound, 113, 2019: 375-379.

Contesse, Jorge. The Final Word? Constitutional Dialogue and the Inter-American Court of Human Rights (2017) 15 ICON.

Contesse, Jorge. Contestation and Deference in the Inter-American Human Rights System. Law \& Contemp. Probs. 7 (2), 2016.

Contreras, Pablo. Control de convencionalidad, deferencia internacional y discreción nacional en la jurisprudencia de la Corte Interamericana de Derechos Humanos. Ius et Praxis, 20, n. 2, 2014: 235.

De Londras, Fionna y Dzehtsiarou, Kanstantsin. Managing Judicial Innovation in the European Court of Human Right. Human Rights Law Review, 2015, 15, 2015: 523-547.

De Londras, Fionna y Dzehtsiarou, Kanstantsin. Grand Chamber of the European Court of Human Rights, A, B and C v Ireland, Decision of 17 December 2010 (2013). 62 International and Comparative Law Quarterly, 250.

Dondoli, Giulia. An overnight success a decade in the making: Indirect discrimination on the grounds of sexual orientation. International Journal of Discrimination and the Law 18.1, 2018, 5-21.

Dothan, Shai. Judicial Deference Allows European Consensus to Emerge. Chicago Journal of International Law, Vol. 18, No. 2, 2018: 393-419.

Dzehtsiarou, K. y Lukashevich, V. Informed Decision-Making: The Comparative Endeavours of the Strasbourg Court. Netherlands Quarterly of Human Rights, 30, 3, 2012: 272-298.

Dzehtsiarou, Kanstantsin. European Consensus: A Way of Reasoning, University College Dublin Law Research Paper No. 11/2009.

Dzehtsiarou, Kanstantsin. European Consensus and the Legitimacy of the European Court of Human Rights, cup, Cambridge, 2015.

Edel, Frederic. Case Law of the European Court of Human Rights relating to discrimination on grounds of sexual orientation or gender identity. LGBT rights are human rights, Council of Europe, 2015. 
Engstrom, Par. Between Hope and Despair: Progress and Resilience in the Inter-American Human Rights System. AJIL Unbound, 113, 2019: 370-374.

Farahat, Anuscheh. Enhancing 'Constitutional Justice' by Using External References: The ECtHR's Reasoning on the Protection against Expulsion. LJIL, 28, 2015: 303-322.

Fenwick, H. Same sex unions at the Strasbourg Court in a divided Europe: driving forward reform or protecting the Court's authority via consensus analysis? European Human Rights Law Review, 3, 2016: 249-272.

FøLLESDAL, ANDREAs. Exporting the margin of appreciation: Lessons for the Inter-American Court of Human Rights. International Journal of Constitutional Law, Vol. 15(2), abril, 2017: 359-371.

Gargarella, Roberto. Sin lugar para la soberanía popular. Democracia, derechos y castigo en el caso Gelman, 2013, selA.

Gerards, Janneke. Margin of Appreciation and Incrementalism in the Case Law of the European Court of Human Rights, Human Rights Law Review 18(3), 2018: 495-515.

Gorzoni, Paula. Der margin of appreciation beim Europäischen Gerichtshof für Menschenrechte: Eine prinzipientheoretische Rekonstruktion, Vol. 71. Nomos Verlag, Baden-Baden, 2019.

Helfer, Laurence R. y Voeten, Erik. International Courts as Agents of Legal Change: Evidence from LGBT Rights in Europe, 68 INT'L ORG. 77, 106 (2014).

IgLESIAS, Marisa. Subsidiarity, margin of appreciation and international adjudication from a cooperative conception of human rights. En Int'l J. Const. L., Vol. 15, n. ${ }^{\circ} 2,2017$.

JACKSON VICKI. Constitutional Comparisons: Convergence, Resistance, Engagement. 119 Harv. L. Rev. 109 (2005).

JACKSON, VICKI. Constitutional Engagement in a Transnational Era, Oxford: oup, 2010.

Johnson, P. The Council of Europe and the European Court of Human Rights. En ZiEgLer, A. R. (ed.), International LGBTI Law: Sexual Orientation and Gender Identity Law from an International-Comparative Perspective, 2018, 5-28.

Kleinlein, Thomas. Consensus and Contestability: The ecthr and the Combined Potential of European Consensus and Procedural Rationality Control. European Journal of International Law 28, 3, 2017: 871-893.

LANDFried, Christine, Internationale Gerichte und nationale Demokratie. En Croissant, A., et al., Demokratie, Diktatur, Gerechtigkeit. Springer, Wiesbaden, 2017, 371-385.

LEGG, ANDREw. The Margin of Appreciation in International Human Rights Law: Deference and Proportionality, oup, Oxford, 2012.

Letsas, G. A Theory of Interpretation of the European Convention on Human Rights, Oxford University Press, Oxford, 2009.

Letsas, G. The Truth in Autonomous Concepts: How to Interpret the ECHR. 15 EJIL, 2004: 279. 
Lixinski, LuCAs. The Consensus Method of Interpretation by the Inter-American Court of Human Rights. Can. J. Comp. \& Contemp. L. 3, 2017: 65-95.

LIXINSKI, LuCAS. Treaty Interpretation by the Inter-American Court of Human Rights: Expansionism at the Service of the Unity of International Law. 21 Eur. J. Int'l L. 585, 2010.

Nash Rojas, Claudio. La doctrina del margen de apreciación y su nula recepción en la jurisprudencia de la Corte Interamericana de Derechos Humanos. Anuario Colombiano de Derecho Internacional 11, 2018: 71-100.

Neumann, Gerald. Import, Export, and Regional Consent in the Inter-American Court of Human Rights. 19 EUR. J. INT'L. LAW 101, 2008: 107.

Parra Vera, Oscar. Algunos aspectos procesales y sustantivos de los diálogos recientes entre la Corte Interamericana de Derechos Humanos y el Tribunal Europeo de Derechos Humanos. En Santolaya/Wences (coords.), La América de los Derechos, CEC, Madrid, 2016, 565-606.

Parra Vera, Oscar y Huber, Florián. Orientación sexual, derechos de las niñas y los niños y no discriminación: Comentarios al caso Atala Riffo y Niñas. En v. Bogdandy/ Piovesan/Morales-Antoniazzi (coords.), Igualdad y Orientación Sexual. México, Porrúa, 2012, 167-208.

Pérez, A. Una mirada desde América Latina sobre el margen de apreciación estatal en el Tribunal Europeo de Derechos Humanos: ¿génesis de una permanente tensión entre democracia y derechos? Revista Jurídica de la Universidad de Palermo (2017), 15, 1.

Petkova, Byliana, The Notion of Consensus as a Route to Democratic Adjudication? 14 Cambridge Yearbook of European Legal Studies, 2013: 663.

Piovesan, Flavia. Proteçao dos Direitos Humanos: uma Análise Comparativa dos Sistemas Regionais Europeu e Interamericano, en v. Bogdandy, A. et al. Direitos Humanos, Democracia e Integraçao jurídica. Río de Janeiro, Lumen Iuris, 2011.

Ragone, Sabrina; Volpe, V. An Emerging Right to a 'Gay' Family Life? The Case Oliari v. Italy in a Comparative Perspective. German Law Journal, 17(3), 2016: 451-486.

Robinson, Tracy. Legalising norms related to sexual, gender and bodily diversity in the inter-American human rights system, SELA, 2017.

Sánchez Molina, P. Margen de apreciación nacional (en los sistemas de protección internacional de los derechos humanos). Eunomía. Revista en Cultura de la Legalidad. 2015.

Saul, Matthew. The European Court of Human Rights' Margin of Appreciation and the Processes of National Parliaments. Human Rights Law Review, Vol. 15, n. ${ }^{\circ}$ 4, 2015 : 745-774.

Shahid, Masuma, The Right to Same-Sex Marriage: Assessing the European Court of Human Rights' Consensus-Based Analysis in Recent Judgments Concerning Equal Marriage Rights. Erasmus Law Review, Nro. 3, 2017: 183-197.

Sieckmann, Jan-R. La teoría del derecho de Robert Alexy. Análisis y Crítica. No. 67. U. Externado de Colombia, 2014. 
SjöHolm, Maria. Gender-sensitive norm interpretation by regional human rights law systems, 2018, Brill/Nijhoff, Holland.

Smet, Stijn, X. and Others v. Austria (Part II): A Narrow Ruling on a Narrow Issue. Prohibition of Discrimination, X. and Others v. Austria, March 6, 2013, Starssbourgh Observer.

Soley, Ximena y Steininger, Silvia. Parting ways or lashing back? Withdrawals, backlash and the Inter-American Court of Human Rights. International Journal of Law in Context 14.2, 2018: 237-257.

Spano, Robert. Universality or Diversity of Human Rights? Strasbourg in the Age of Subsidiarity. Human Rights Law Review, Vol.14, n. $3,2014$.

SÜNDHOFER, BEATE. Konventionskonformität des Gesichtsbedeckungsverbots in der Öffentlichkeit. En $A L J$ (2015), 88-98.

Taiana, Jorge. The Legacy and Current Challenges of the Inter-American Commission on Human Rights. Human Rights Brief 20, no. 2 (2013), 42-45.

TSERETELI, Nino. Emerging Doctrine of Deference of the Inter-American Court of Human Rights (2016). 20 Int'l J of Human Rights 1097. 1107.

Wildhaber, L., et al. No Consensus on Consensus? The Practice of the European Court Of Human Rights, Human Rights Law Journal, 33, 2013, 248-263.

Zucca, Lorenzo. Lautsi: A Commentary on a Decision by the ecthr Grand Chamber. International Journal of Constitutional Law, 2013, 218-229. 